\title{
EVERY 8-TRACEABLE ORIENTED GRAPH IS TRACEABLE
}

\author{
SUSAN A. VAN AARDT ${ }^{1}$ \\ Department of Mathematical Sciences \\ University of South Africa \\ P.O. Box 392, Unisa, 0003 South Africa \\ e-mail: vaardsa@unisa.ac.za
}

\begin{abstract}
A digraph of order $n$ is $k$-traceable if $n \geq k$ and each of its induced subdigraphs of order $k$ is traceable. It is known that if $2 \leq k \leq 6$, every $k$-traceable oriented graph is traceable but for $k=7$ and for each $k \geq 9$, there exist $k$-traceable oriented graphs that are nontraceable. We show that every 8-traceable oriented graph is traceable.
\end{abstract}

Keywords: oriented graph, traceable, hypotraceable, $k$-traceable, generalized tournament.

2010 Mathematics Subject Classification: 05C20, 05C38.

\section{REFERENCES}

[1] S.A. van Aardt, A.P. Burger, J.E. Dunbar, M. Frick, J.M. Harris and J.E. Singleton, An iterative approach to the Traceabiltiy Conjecture for Oriented Graphs, Electron. J. Combin. 201 (2013) \#P59.

[2] S.A. van Aardt, A.P. Burger, M. Frick, B. Llano and R. Zuazua, Infinite families of 2-hypohamiltonian/2-hypotraceable oriented graphs, Graphs Combin. 30 (2014) 783-800.

doi:0.1007/s00373-013-1312-1

[3] S.A. van Aardt, J.E. Dunbar, M. Frick, P. Katrenič, M.H. Nielsen and O.R. Oellermann, Traceability of $k$-traceable oriented graphs, Discrete Math. 310 (2010) 1325-1333.

doi:10.1016/j.disc.2009.12.022

\footnotetext{
${ }^{1}$ Supported by the National Research Foundation of S.A, Grant 81075.
} 
[4] S.A. van Aardt, J.E. Dunbar, M. Frick and M.H. Nielsen, Cycles in $k$-traceable oriented graphs, Discrete Math. 311 (2011) 2085-2094.

doi:10.1016/j.disc.2011.05.032

[5] S.A. van Aardt, J.E. Dunbar, M. Frick, M.H. Nielsen and O.R. Oellermann, A traceability conjecture for oriented graphs, Electron. J. Combin. 15 (2008) \#R150.

[6] S.A. van Aardt, M. Frick, P. Katrenič and M.H. Nielsen, The order of hypotraceable oriented graphs, Discrete Math. 11 (2011) 1273-1280. doi:10.1016/j.disc.2011.03.009

[7] A.P. Burger, Computational results on the traceability of oriented graphs of small order, Electron. J. Combin. 20 (2013) \#P23.

[8] J. Bang-Jensen and G. Gutin, Digraphs: Theory, Algorithms and Applications, Second Ed. (Springer-Verlag, London, 2009). doi:10.1007/978-1-84800-998-1

[9] M. Frick and P. Katrenič, Progress on the traceability conjecture, Discrete Math. Theor. Comput. Sci. 10 (2008) 105-114.

[10] M. Grötschel and Y. Wakabayashi, Constructions of hypotraceable digraphs, in: Mathematical Programming, R.W. Cottle, M.L. Kelmanson and B. Korte (Ed(s)), (Elsevier Science Publishers B.V., 1984).

Received 6 January 2016

Revised 10 August 2016

Accepted 10 August 2016 